\title{
Las nuevas caras de la dolorosa pandemia COVID-19
}

\author{
The new faces of the painful COVID-19 pandemic
}

\author{
Jaime Salazar-Zuloeta ${ }^{(1, a),}$ Rosío Pando-Lazo (1,b)
}

\section{Sr. Editor:}

En relación al contenido del artículo especial titulado "Desafíos para el manejo y detección de pacientes con COVID-19 en Latinoamérica", los autores expresamos que es pertinente el abordaje que hace el autor a la luz de los conocimientos disponibles sobre diagnóstico y prevención de esta grave enferme-dad. Después de afectar Asia y Europa, el SARS-CoV-2 ingresó con inusitada fuerza en América latina, vulnerable por sus frágiles sistemas de salud y, por tanto, susceptible de una afectación no solo en término de vidas humanas, sino daño social y económico difícil de recuperar (1).

Después de que la COVID-19 empezara en el Perú como problema focalizado, hoy nos encontramos en un escenario de trasmisión comunitaria e innegable propagación nosocomial del SARS-CoV-2, en especial cuando se realizan procedimientos invasivos como intubación endotraqueal (2).

Esta pandemia ha mostrado las falencias de nuestro sistema sanitario para hacer frente a una de-manda creciente de personas frágiles, susceptibles de desarrollar procesos severos como neumonía, síndrome de distrés respiratorio del adulto, sepsis, shock séptico y falla multiorgánica. Por tanto, como muy bien sostiene el autor del artículo mencionado al empezar esta carta, controlar la pandemia es, sin duda alguna, un camino lleno de esfuerzos para que el gobierno, de acuerdo a la Constitución Po-lítica del Estado, pueda garantizar la seguridad y vida de cada uno de los peruanos, en especial los de pobreza extrema.

En vista que hasta el momento no existe un medicamento de elección eficaz y seguro contra el SARS-CoV-2, quedan entonces dos desafíos: el primero, contar, en cada una de las regiones del Perú, con un número suficiente de pruebas moleculares y serológicas y el segundo desafío es disponer de la logística para atender al paciente, muy en especial al paciente grave y con factores de riesgo.

Actualmente, las pruebas moleculares (RT-PCR o Reacción en cadena de Polimerasa en tiempo real) son los métodos de elección para el diagnóstico de la infección por el SARS-COv-2 y permiten confir-mar la presencia del virus en muestras de vía aérea superior o inferior desde que se inicia la replicación viral. Una revisión sistemática mostró que la sensibilidad y especificidad de este tipo de pruebas fue de $81,4 \%$ de sensibilidad y $100 \%$ de especificidad ${ }^{(3)}$. Desde el mes de agosto, la Gerencia Regional de Salud de Lambayeque cuenta con la tecnología para realizar pruebas moleculares y descartar CO-VID-19 en solo 4 horas ${ }^{(4)}$.

\footnotetext{
1. Facultad de Medicina Humana. Universidad Nacional Pedro Ruiz Gallo. Lambayeque. Lambayeque, Perú.

a Magister en Ciencias con Mención en Gerencia de Servicios de Salud. Profesor Asociado.

${ }^{\mathrm{b}}$ Médico Cirujano. Profesor Auxiliar. Facultad de Medicina Humana.
} 
A diferencia de las pruebas moleculares, las "pruebas rápidas" o serológicas pueden salir negativas en el momento en que el paciente infectado con el SARS-CoV-2 aún no ha producido anticuerpos específicos contra este patógeno y solo detectan la infección después de 7 a 10 días del inicio de los síntomas, por lo que la potencia diagnóstica de estas pruebas aumenta de modo directamente proporcional al tiempo transcurrido, llegando a sensibilidad del $88,66 \%$ y especificidad del $90,63 \%{ }^{(5)}$. El tema es que estas pruebas rápidas, sencillas para realizarse masivamente, pueden dar falsos positivos y falsos negativos, y se debe tener cuidado en la interpretación porque pueden detectar lgG e lgM contra el SARS-CoV-2, solo indica infección o contacto con el virus pero la prueba no permite discriminar si la infección es activa o pasada (paciente inmune) ${ }^{(5)}$, y por este motivo, ante las discordancias, el manejo siempre debe ser individualizado, visto que la respuesta inmune es distinta de una a otra persona y debemos razonar y tomar decisiones en función de la clínica del paciente y, de ser necesario, complementar con la tomografía pulmonar ${ }^{(6)}$.

Por otro lado, está demostrado que el SARS-CoV-2 se puede trasmitir por medio de aerosoles ${ }^{(7),(8)}$, eso nos obliga a reforzar la necesidad de que los servicios hospitalarios, asignados "oficialmente" o no al manejo de pacientes enfermos por la COVID-19, tengan las condiciones adecuadas para minimizar la contaminación del ambiente y de igual forma asegurar provisión de los equipos de protección personal (EPP), en especial si durante la atención del paciente se podrían generar aerosoles potencialmente infectantes. Además, se requiere la prolija limpieza y desinfección de todas las superficies que tocamos dentro y fuera de nuestro ambiente de trabajo como medidas de prevención, debido a que el virus es capaz de mantenerse infectante muchas horas después de contaminar superficies plásticas o metálicas (9) (10).

En conclusión, podemos afirmar que aún se necesita la articulación permanente entre clínicos y personal de ayuda al diagnóstico; debemos trabajar en un solo Sistema para poder superar al SARS-CoV-2, pero por ahora tenemos la difícil misión de evitar que se siga infectando el personal de salud, exigir disponer de EPP y pruebas moleculares y serológicas de manera permanente, además de respetar estrictamente las medidas de higiene.

Conflictos de interés: Los autores declaran no tener conflictos de interés en esta publicación.

Fuentes de financiamiento: Autofinanciado

\section{REFERENCIAS BIBLIOGRÁFICAS}

1. Caribe CE para AL y el. Salud y economía: una convergencia necesaria para enfrentar el COVID-19 y retomar la senda hacia el desarrollo sostenible en América Latina y el Caribe [Internet]. CEPAL; 2020 [citado 14 de octubre de 2020]. Disponible en: https://www.cepal.org/es/publicaciones/45840-salud-economia-convergencia-necesaria-enfrentar-covid-19-retomar-la-senda

2. Tran K, Cimon K, Severn M, Pessoa-Silva CL, Conly J. Aerosol Generating Procedures and Risk of Transmission of Acute Respiratory Infections to Healthcare Workers: A Systematic Review. PLoS ONE [Internet] 2012 [citado 14 de octubre de 2020];7(4). Disponible en: https://www. ncbi.nlm.nih.gov/pmc/articles/PMC3338532/

3. Duarte ML, Santos LR dos, Contenças AC de S, lared W, Peccin MS, Atallah ÁN. Reverse-transcriptase polymerase chain reaction versus chest computed tomography for detecting early symptoms of COVID-19. A diagnostic accuracy systematic review and meta-analysis. Sao Paulo Med J [Internet]. 19 de agosto de 2020 [citado 5 de octubre de 2020]; Disponible en: http://www.scielo.br/scielo.php?script=sci_arttext\&pi$\mathrm{d}=$ S1516-31802020005018201\&tIng =en

4. Equipo de diagnóstico para pruebas moleculares ya está instalado en el laboratorio referencial regional de salud [Internet]. [citado 14 de octubre de 2020]. Disponible en: https://www.regionlambayeque.gob.pe/web/ noticia/detalle/31121?pass $=\mathrm{Mg}==$

5. Calvache JMM, Rodríguez ADE, Martínez CBC, Paucar VAV. Utilidad de Pruebas de cadena de polimerasa, pruebas rápidas y Tomografías en pacientes con Covid-19. Journal of America health. 17 de julio de 2020;3(2):32-9

6. Ortiz AFH, Ordoñez JCD, Castaño MFM, Pérez CM de la P, Niño FAM. Patrones característicos de COVID-19 en tomografía de tórax: una revisión de la literatura. Revista Neuronum ISSN: 2422-5193 (En línea). 9 de julio de 2020;6(4):350-68.

7. Anderson EL, Turnham P, Griffin JR, Clarke CC. Consideration of the Aerosol Transmission for COVID-19 and Public Health. Risk Analysis. 2020;40(5):902-7.

8. Kohanski MA, Palmer JN, Cohen NA. Aerosol or droplet: critical definitions in the COVID $\square 19$ era. Int Forum Allergy Rhinol. agosto de 2020;10(8):968-9.

9. Suman R, Javaid M, Haleem A, Vaishya R, Bahl S, Nandan D. Sustainability of Coronavirus on Different Surfaces. Journal of Clinical and Experimental Hepatology. 1 de julio de 2020;10(4):386-90.

10. Zhang S, Wang C, Lin M, Deng Q, Ye Y, Li Z, et al. Analysis of the Virus Contamination and Disinfection Effect in Isolation Ward of Patients With COVID-19. Front Public Health [Internet]. 2020 [citado 24 de septiembre de 2020];8. Disponible en: https://www.frontiersin.org/articles/10.3389/ fpubh.2020.00486/full. 